Original Paper

\title{
Workshop Teknik Pembimbingan dan Penilaian Mahasiswa Peserta Praktek Pengenalan Lapangan Persekolahan Bagi Guru-Guru Anggota KKG di Kota Mataram
}

\author{
A Wahab Jufri ${ }^{1}$, Ni Made Novi Suryanti ${ }^{1}$, M. Amin ${ }^{1}$, Abdul Kadir Jaelani ${ }^{1}$, Dadi Setiadi ${ }^{1 *}$ \\ ${ }^{1}$ Program Studi Magister Administrasi Pendidikan, Pascasarjana, Universitas Mataram, Indonesia
}

DOI: $10.29303 /$ jpmpi.v2i2.373

Sitasi: Jufri, A. W., Suryanti, N. M. N., Amin, M., Jaelani, A. K., Setiadi, D. (2019). Workshop Teknik Pembimbingan dan Penilaian Mahasiswa Peserta Praktek Pengenalan Lapangan Persekolahan Bagi Guru-Guru Anggota KKG di Kota Mataram. Jurnal Pengabdian Magister Pendidikan IPA (JPMPI). (2) 2. pp. 133-138

*Corresponding Author: Dadi Setiadi, Program Studi Magister Administrasi Pendidikan, Pascasarjana, Universitas Mataram, Indonesia; Email: setiadi_dadi@unram.ac.id

\begin{abstract}
Abstrak: Sesuai dengan stándar pendidikan guru bahwa mahasiswa program sarjana kependidikan harus mengikuti mata kuliah pengenalan lapangan persekolahan di satuan pendidikan. Untuk mencapai tujuan pelaksanaan PLP tersebut perlu didukung oleh pembimbing dari unsur guru yang memahami secara teknis pembimbingan dan evaluasi mahasiswa peserta PLP, juga agar dapat mengarahkan mahasiswa untuk bisa memiliki kemampuan terkait dengan program sekolah, perangkat pembelajaran dan praktek mengajar. Berdasarkan studi pendahuluan para guru SD belum memiliki pemahaman yang sama tentang teknik pembimbingan dan evaluasi mahasiswa peserta PLP, sehingga perlu dilakukan workshop kepada guru-guru SD tersebut agar mampu membimbing dan mengevaluasi hasil PLP mahasiswa. Tujuan kegiatan pengabdian yang dilakukan adalah untuk Mengembangkan pemahaman guru anggota KKG Kota Mataram dalam membimbing dan mengevaluasi kemampuan mahasiswa dalam menyusun program sekolah, perangkat pembelajaran; Mengembangkan keterampilan guru guru anggota KKG Kota Mataram dalam membimbing dan mengevaluasi mahasiswa peserta PLP. Metode yang digunakan dalam pengabdian ini adalah melalui workshop yang lebih berbasis pada praktek langsung teknik pembimbingan dan penilaian mahasiswa peserta PLP yang dapat meningkatkan kemampuan dalam mengarahkan dan membimbing mahasiswa peserta PLP. Kegiatan pengabdian dilaksanakan dengan tahapan sebagai berikut : Studi literatur, analisis kebutuhan guru berupa pemahaman dan keterampilan guru dalam membimbing dan mengevalausi hasil PLP, pengukuran kemampuan awal guru, mendisain program workshop, pelaksanaan workshop: berupa kajian pembimbingan peserta PLP, praktek mendisain instrumen evaluasi PLP, pemantauan dan bimbingan di lapangan oleh tim pengabdian pada masyarakat, asesmen kualitas pelaksanaan dan hasil akhir workshop peserta dan, penyusunan laporan PPM.. Hasil kegiatan menunjukan bahwa Sebagian besar guru memiliki pemahaman secara komprehensif mengenai teknik-teknik pembimbingan, pelaksanaan praktek pengenalan lapangan persekolahan, mengevaluasi proses dan memiliki keterampilan dalam mendisain instrumen observasi dan ecvaluasi: membimbing mahasiswa, mengevaluasi proses dan hasil, membimbing penyeusunan laporan praktek pengenalan lapagan persekolahan.Dengan demikian guru akan mampu membimbing mahasiswa PLP dan melakukan evaluasinya secara baik.
\end{abstract}

Kata kunci: Workshop; Teknik Bimbingan; Pengalaman Lapangan Persekolahan (PLP)

\section{Pendahuluan}

Kualitas hasil pendidikan di pendidikan dasar dan menengah sangat tergatung pada guru khususnya bagaimana guru bisa melaksanakan tugas dalam mengelola pembelajaran sesuai dengan tagihan standar proses pembelajaran. Selain itu, kualitas hasil belajar peserta didik masih belum sesuai dengan tagihan kurikulum, sehingga perlu dilakukan pembenahan atau perbaikan terkait 
dengan hal tersebut. Banyak usaha yang telah dilakukan oleh pemerintah dalam usaha meningkatkan mutu pendidikan di satuan pendidikan diantaranya dengan membuat 8 standar pendidikan yang harus dipenuhi oleh setiap satuan pendidikan. Juga standar program sarjana kependidikan dengan di keluarkannya standar pendidikan guru (SPG) yang berupa Permenristekdikti No 55 Tahun 2017.

Standar pendidikan guru merupakan satu standar yang harus dipenuhi oleh lembaga pendidik tenaga kependidikan, sehingga diharapkan lulusan sarjana pendidikan guru memiliki kompetensi yang sesuai dengan kebutuhan di lapangan sebagai calon guru profesional. Kompetensi tersebut mencakup kompetensi profesional, pedagogi, sosial dan kepribadian. Dalam konteks standarisasi standar pendidikan guru tersebut khususnya dengan penentuan capaian pembelajaran lulusan untuk sarjana pendidikan yang terkait dengan standar isi termasuk mata kuliah yang wajib dilaksanakan oleh penyelenggara pendidikan sarjana pendidikan diantaranya adalah mata kuliah pengenalan lapangan persekolahan (PLP) 1 dan 2 sesuai dengan Permenristekdikti No 55 tahuan 2017. Kedua mata kuliah tersebut sesuai pedoman PLP dilaksanakan di sekolah dan di kampus, dan mata kuliah pengenalan lapangan persekolahan 1 dilaksanakan pada semester 3 atau 4, sedangkan mata kuliah pengenalan lapangan persekolah 2 dilaksanakan pada semester 6 dan 7 .

Menurut Kemenristekdikti (2017) bahwa PLP merupakan mata kuliah dan merupakan suatu tahapan dalam proses penyiapan guru profesional pada jenjang program sarjana pendidikan, berupa penugasan kepada mahasiswa untuk mengimplementasikan hasil belajar melalui pengamatan proses pembelajaran di sekolah atau lembaga pendidikan, latihan mengembangkan perangkat pembelajaran, dan belajar mengajar terbimbing, serta disertai tindakan reflektif di bawah bimbingan dan pengawasan dosen pembimbing dan guru pamong secara berjenjang.

Menurut Direktorat Jenderal Pembelajaran dan Kemahasiswaan ( 2017) PLP I dimaksudkan untuk membangun landasan jati diri pendidik melalui beberapa bentuk kegiatan di sekolah sebagai berikut; Pengamatan langsung kultur sekolah; Pengamatan struktur organisasi dan tata kelola di sekolah; Pengamatan peraturan dan tata tertib sekolah; Pengamatan kegiatan-kegiatan ceremonialformal di sekolah (misalnya: upacara bendera, rapat briefing); Pengamatan kegiatan-kegiatan rutin berupa kurikuler, kokurikuler, dan ekstrakurikuluer; dan Pengamatan praktik-praktik pembiasaan dan kebiasaan positif di sekolah.

Inti dari kegiatan PLP I adalah aktivitas observasi, analisis dan penghayatan langsung terhadap kegiatan terkait dengan kultur sekolah, manajemen sekolah, dan dinamika sekolah sebagai lembaga pengembang pendidikan dan pembelajaran. Inti dari kegiatan PLP I adalah aktivitas observasi, analisis dan penghayatan langsung terhadap kegiatan terkait dengan kultur sekolah, manajemen sekolah, dan dinamika sekolah sebagai lembaga pengembang pendidikan dan pembelajaran. Selain itu mendeskripsikan karakteristik umum peserta didik yang kelak akan menjadi tanggung jawab dalam praksis kependidikan, mendeskripsikan struktur organisasi dan tata kerja sekolah, peraturan dan tata tertib sekolah, mengidentifikasi kegiatan-kegiatan seremonial-formal di sekolah dan kegiatan-kegiatan rutin berupa kurikuler, kokurikuler dan ekstrakurikuluer, dan mendeskripsikan praktikpraktik pembiasan dan kebiasan positif di sekolah.

Menurut Direktorat Jenderal Pembelajaran dan Kemahasiswaan (2017) Pengenalan Lapangan Persekolahan II (PLP II) adalah tahapan kedua dalam pengenalan lapangan persekolahan program sarjana pendidikan yang dilaksanakan pada semester keenam atau ketujuh. Sebagai tahap lanjutan dari PLP I, PLP II dimaksudkan untuk memantapkan kompetensi akademik kependidikan dan bidang studi melalui berbagai bentuk aktivitas di sekolah. Pada PLP II para mahasiswa diharapkan dapat memantapkan kompetensi akademik kependidikan dan bidang studi yang disertai dengan kemampuan berpikir kritis dan kemampuan berpikir tingkat tinggi melalui kegiatan sebagai berikut: menelaah kurikulum dan perangkat pembelajaran yang digunakan guru; menelaah strategi pembelajaran yang digunakan guru; menelaah sistem evaluasi yang digunakan guru; . membantu guru dalam mengembangkan RPP, media pembelajaran, bahan ajar, dan perangkat evaluasi; menelaah pemanfaatan teknologi informasi dan komunikasi dalam pembelajaran; latihan mengajar dengan bimbingan guru pamong dan dosen pembimbing PLP II, dengan tujuan merasakan langsung proses pembelajaran, serta pemantapan jati diri calon pendidik; melaksanakan tugas-tugas pendampingan peserta didik dan kegiatan ekstrakurikuler; dan membantu guru dalam 
melaksanakan tugas-tugas pekerjaan administasi guru.

Namun demikian, berdasarkan pertimbangan dan studi di lapangan Asosiasi FKIP Negeri se Indonesia menunjukan bahwa kondisi mahasiswa di semester awal (3 atau 4) belum memahami persekolahan secara menyeluruh, sehingga akan kesulitan dalam pelaksanaan PLP 1. Selain itu, kondisi dan jumlah sekolah lokasi yang sangat terbatas termasuk juga digunakan oleh LPTK lain atau swasta, sehingga sulit untuk bisa dilaksanakan sesuai peraturan tersebut. Dengan demikain mata kuliah tersebut digabung menjadi mata kuliah PLP dengan jumlah SKS sama dan dilaksanakan pada semester 6 atau 7 setelah mahasiswa memenuhi persyaratan-persyaratan tertentu untuk bisa melaksankan PLP.

Dalam konteks implementasi mata kuliah PLP di sekolah diperlukan persiapan yang memadai karena melibatkan banyak personal seperti dosen pembimbing, guru pamong, penyelenggara, kepala sekolah, juga pedoman pelaksanakan PLP dan teknis pelaksanaan mulai dari perencanaan sampai dengan pengukuran hasil pelaksanaan PLP yang tidak hanya menyangkut nilai mahasiswa tetapi termasuk penyelengaraannya. Berdasarkan uraian di atas maka salah satunya perlu dilakukan Workshop Teknik Pembimbingan dan Penilaian Mahasiswa Peserta Praktek Pengenalan Lapangan Persekolahan Bagi Guru-Guru Anggota KKG di Kota Mataram..

\section{Metode Pelaksanaan}

Tempat pelaksanaan kegiatan PPM di FKIP UNRAM tahun akademik 2019/2020. Model pelaksanaan yang digunakan dalam pengabdian ini adalah workshop, peserta diberikan penjelasan tentang materi workshop teknik pembimbingan dan penilaian mahasiswa peserta praktek pengenalan lapangan persekolahan bagi guru-guru anggota KKG di Kota Mataram dan kemudian diberikan tugas kerja untuk melakukan pembimbingan mahasiswa peserta PLP. dalam bentuk kelompok. Populasi adalah semua guru anggota KKG Kota Mataram, sampel yang digunakan sebanyak 40 orang guru. Pengumpulan data dilakukan dengan mengevaluasi hasil berupa pengetahun dan keterampilan tentang teknik pembimbingan dan penilaian mahasiswa peserta praktek pengenalan lapangan persekolahan. Hasil
PPM berupa data skor kuantitatif dan kualitatif dan dianalisis secara deskriptif kualitatif (Sugiyono, 2008a: 2008b).

\section{Hasil dan Pembahasan}

Sebagian besar guru (90\%) memiliki pemahaman secara komprehensif mengenai teknik-teknik pembimbingan mahasiswa peserta praktek pengenalan lapangan persekolahan. Pemahaman guru berhubungan dengan tagihan dari teknik pembimbingan dan menunjukan pemahaman yang jauh lebih baik dibanding dengan sebelumnya, hal ini memberikan rasa optimisme pada yang bersangkutan untuk bisa membimbing mahasiswa PLP. Dengan demikian guru-guru akan mampu mendukung pelaksanaan PLP amahsiswa FKIP UNAM.

Semua guru memiliki pemahaman secara komprehensif mengenai teknik-teknik mengevaluasi proses dan hasil pelaksanaan praktek pengenalan lapangan persekolaha. Pemahaman guru yang berhubungan dengan teknik mengevalausi proses dan hasil PLP menunjukan pemahaman yang jauh lebih baik dibanding dengan sebelumnya, hal ini memberikan peluang bahwa pelaksanaan evaluasi akan terlaksana sesuai dengan SOP. Dengan demikian guru-guru pamong akan mampu menyusun instrumen penilaian pengetahuan, sikap dan keterampilan sebagai hasil PLP mahasiswa FKIP UNRAM.

Sebagian besar guru terampil dalam mendisain instrumen observasi dan evaluasi praktek pengenalan lapangan persekolahan. Para guru telah memiliki keterampilan dalam mendisain instrumen observasi dan evaluasi. Juga guru telah terampil dalam menjabarkan tagihan kompetensi PLP menjadi sejumlah indikator pencapaian kompetensi, sehingga para guru tidak akan mengalami kesulitan ketika mendisan indikator pencapain kompetensi PLP 1 dan 2. Juga ketika menyusun instrumen asesmen sikap dan keterampilan dalam PLP 2 akan sesuai dengan tagihan yang ada pada dokumen tujuan PLP.

Sebagian besar guru terampil dalam membimbing mahasiswa peserta praktek pengenalan lapangan persekolahan. Para guru peserta telah memiliki keterampilan dalam dalam membimbing mahasiswa PLP. Juga guru telah terampil dalam menjabarkan tagihan kompetensi PLP dalam bimbingan sehingga bisa mencapai 
proses dan hasil yang baik. Selain itu diharapkan para guru bisa mengembangkan proses bimbingan PLP sehingga hasilnya akan jauh lebih baik.

Sebagian besar guru terampil dalam mengevaluasi proses dan hasil pelaksanaan praktek pengenalan lapangan persekolahan. Hal tersebut menunjukan proses evaluasi PLP 1 dan 2 akan terlaksana dengan baik, namun demikian masih perlu bimbingan yang lebih baik dari tim pengabdian agar keterampilan tersebut bisa dimiliki oleh guru tersebut.

Sebagian besar guru sudah terampil dalam membimbing penyusunan laporan praktek pengenalan lapagan persekolahan. Proses penyusuan laporan memerlukan waktu sehingga gurupun harus tetap teliti dalam membimbing mahasiswa peserta PLP, sehingga para mahasiswa tersebut bisa melaporkan dalam bentuk tulisan yang bisa dipertanggung jawabkan dengan tetap berpedoman pada aturan dan etika akademik. Selain itu masih perlu pemantapan terkair dengan guru karena beliau belum terbiasa membimbing dalam membuat suatu laporan PLP yang baik yang memenuhi tagihan dan ketentuan yang berlaku.

Guru peserta pengabdian telah memiliki pemahaman secara komprehensif mengenai teknikteknik pembimbingan mahasiswa peserta praktek pengenalan lapangan persekolahan. Hal tersebut menunjukan bahwa proses pelaksanaan workshop sudah cukup baik sehingga bisa menunjukan bahwa tujuan telah dicapai dengan baik. Namum masih perlu perbaikan perbaikan dalam persiapan dan proses serta ketika peserta tersebut kembali ke sekolah masing-masing. Dengan demikian proses pembimbingan as mentors are meant to support and guide this process with the comments and feedback they provide in order to help prospective teachers acquire teaching skills (Genc, 2016) dan bimbingan di sekolah dan komunikasi dalam proses ril pembimbingan mahasisa PLP perlu tetap dilakukan dengan teknik komunikasi yang baik dengan para calon guru pamong mahasiswa PLP tersebut serta ada five primary mentoring roles: 'self-trainer', 'networker, 'social supporter', 'academic supporter', and 'psychological supporter'. The results will contribute to an increased understanding of how cooperating teachers perceive their mentoring roles during practicums (Koç, 2012).

Selain itu bahwa guru peserta pengabdian telah memiliki pemahaman secara komprehensif mengenai teknik-teknik mengevaluasi proses dan hasil pelaksanaan praktek pengenalan lapangan persekolahan. Pemahaman tersebut sangat penting dan dibutuhkan ketika guru tersebut mendisain instrumen evaluasi untuk menilai proses dan hasil pelaksanaan PLP. Peserta tersebut tetap harus diminta untuk tetap mengkaji sumber pustaka terkait dengan evaluasi sehingga para calon guru pamong tersebut lebih baik lagi dalam pemahaman yang diperlukan untuk mendisain instrumen evalausi proses dan hasil pelaksanaan PLP. Selain itu assistance of mentors in lesson preparation, methods of presenting lessons, assessment of learners, administration matters, classroom management, maintenance of discipline and professional development (Heeralal, 2014)

Keterampilan guru dalam mendisain instrumen observasi dan evaluasi praktek pengenalan lapangan persekolahan sudah cukup baik. Namun perlu tetap berlatih dalam bentuk pemantapan agar semakin lebih baik lagi ketrampilannya dalam mendisain instrumen evaluasi. Keterampilan tersebut sangat menentukan dalam menggambarkan tingkat pencapaian tujuan PLP, dengan alasan jika kurang tepat maka tidak memberikan gambaran tingkat ketercapaian dari capaian pembelajaran mata kuliah terkait. Peran tim berperan cooperating teachers to enrichtheir skills on mentoring studentteachers and more time for post-conference were recommended (GalamayCachola, Aduca. dan Calauagan, 2018) Sehingga pembimbingan lebih detail lagi dan praktek lebih banyak lagi merupakan cara untuk lebih memberikan pengalaman agar calon guru pamong tersebut bisa memiliki keterampilan tersebut dengan sangat baik.

Guru tampak menguasai dengan baik mengenai teknik membimbing mahasiswa peserta praktek pengenalan lapangan persekolahan. Hal tersebut bisa disebabkan dianataranya dalam proses pelaksanaan pengabdian bisa dilakukan dengan biak sehingga peserta bisa mengikuti dengan baik, disamping itu dalam pembimbingan juga dilakukan dengan baik oleh tim sehingga bisa mencapai tujuan dari kegiatan wrokshop tersebut. Namun demikian bahwa guru harus tetap melakukan pengayaan agar bisa lebih baik lagi dalam pelaksanaan yang sesungguhnya. Selain itu kontrol dari tim perlu tetap dilakukan agar calon guru pamong tersebut tetap memperdalam hal terkait sampai dengan guru tersebut memiliki kompetensi yang diharapkan sehingga bisa menghasilkan mahasiswa yang memiliki kompetensi sesuai dengan capai 
pembelajaran mata kuliah sehingga bisa mendukung pencapaian pembelajaran program studi sesuai dengan beban yang diberikan kepada mata kuliah tersebut. Mentor mampu mebimbing peserta PLP disebabkan mereka pada masa the transition from theory to practice is enhanced and optimised by using a mentoring system, as there are appropriate support mechanisms in place. The value of a mentor system is that it focuses not only on developing appropriate competences, but also has a strong humanist element $\mathrm{n}$ that it concentrates on the person of the student teacher (Frick, Carl, dan Beets, 2010).

Guru terampil dalam mendisain instrumen evaluasi proses dan hasil pelaksanaan praktek pengenalan lapangan persekolahan. Kemampuan tersebut sangat mendukung calon guru pamong dalam membimbing mahasiswa peserta PLP terutama untuk mengukur kualitas proses dan hasil pelaksanaan PLP. Instrumen tersebut harus memenuhi persyaratan agar bisa mengukur proses dan hasil yang memenuhi standar evaluasi. Namun demikian para guru pamong tersebut masih perlu mempebayak lagi latihan dan bimbingan oleh tim agar keterampilan yang dimiliki tersebut bisa dikembangkan oleh para calon guru pamong. Selain itu akan lebih baik jika mentoring diperkaya dengan sistem e-mentoring program had positive influence on their professional development besides the formal education given to the participants. The ementoring program helped students, academicians and graduates share their knowledge and experience with each other and develop their social networks (Kahraman, dan Kuzu, 2016).

Guru terampil dalam teknik membimbing penyusunan laporan praktek pengenalan lapangan persekolahan. Tetapi masih perlu bimbingan dalam praktek yang rill terhadap mahasiswa peserta PLP. Selain itu para guru pamong tersebut belum terbiasa dalam membimbing menyusun tulisan laporan, sehingga calon guru pamong tersebut masih perlu bimbingan dari tim pengabdian agar para guru tersebut memiliki pemahaman dan keterampilan terkait dengan penyusunan laporan PLP. Laporan tersebut harus bisa mencerminkan kualitas proses dan hasil PLP oleh karena itu para pembimbing khususnya guru pamong harus memiliki pemahaman dan keterampilan dalam menyusun laporan PLP.

\section{Kesimpulan}

Sebagian besar guru (90\%) memiliki pemahaman secara komprehensif mengenai teknikteknik pembimbingan, pelaksanaan praktek pengenalan lapangan persekolahan, mengevaluasi proses dan memiliki keterampilan dalam mendisain instrumen observasi dan ecvaluasi: membimbing mahasiswa, mengevaluasi proses dan hasil, membimbing penyesunan laporan praktek pengenalan lapangan persekolahan

\section{Ucapan Terimakasih}

Ucapan Terma Kasih disampaikan kepada Bapak Rektor Universitas Mataram atas dukung dana pelaksanaan PPM dan para guru peserta sebagai calon pembimbing mahasiswa paserta PLP.

\section{Daftar Pustaka}

Direktorat Jenderal Pembelajaran dan Kemahasiswaan, 2017. Panduan Program Pengenalan Lapangan Persekolahan Program Sarjana Pendidikan. Jakarta: Direktorat Pembelajaran Direktorat Jenderal Pembelajaran dan Kemahasiswaan

Frick, L., Carl, A. dan Beets, P. 2010. Reflection as learning about the self in context: mentoring as catalyst for reflective development in pre-service teachers. South African Journal of education. 30. 421-437

Galamay-Cachola, S., Aduca. M. C. M. \&. Calauagan, F.C. 2018. Mentoring Experiences, Issues, and Concerns in the Student-Teaching Program: Towards a Proposed Mentoring Program in Teacher Education

Genc, Z. S., 2016. More Practice for Pre-Service Teachers and More Theory for Inservice Teachers of English Language. Procedia Social and Behavioral Sciences 232. 677 $-683$

Heeralal. P.J.H. 2014. Mentoring Needs of preService Teachers during Teaching Practice. A Case Study at a South African University. Journal of Educational and Social Research. (4) 1

Kahraman, M dan Kuzu, A. 2016. E-Mentoring for Professional Development of Pre-Service 
Teachers: A Case Study. Turkish Online Journal of Distance Education-TOJDE (17) 3.

Kemenristekdikti. 2017. Peraturan Menteri Riset, Teknologi, dan Pendidikan Tinggi Republik Indonesia Nomor 55 Tahun 2017 Tentang Standar Pendidikan Guru; Jakarta: Kemenristekdikti.

Koç, E. M. 2012. Idiographic Roles Of Cooperating Teachers As Mentors In Pre-Service Distance Teacher Education. Teaching and Teacher Education. 28. 818-826.

Sugiyono. 2008a. Memahami Penelitian Kualitatif. Bandung: CV Alfabeta.

Sugiyono. 2008b. MetodePenelitian Pendidikan Pendekatan Kuantitatif, Kualitatif, dan RT $\& D$. Bandung: Alfabeta. 